\title{
Neuroprotective effects of gelsolin during murine stroke
}

\author{
Matthias Endres, ${ }^{1}$ Klaus Fink, ${ }^{2}$ Jinmin Zhu, ${ }^{1}$ Nancy E. Stagliano, ${ }^{3}$ \\ Vimala Bondada, ${ }^{4}$ James W. Geddes, ${ }^{4}$ Toshifumi Azuma, ${ }^{5}$ Mark P. Mattson, ${ }^{4}$ \\ David J. Kwiatkowski, ${ }^{5}$ and Michael A. Moskowitz ${ }^{1}$
}

${ }^{1}$ Stroke and Neurovascular Regulation, Massachusetts General Hospital, Harvard Medical School,
Charlestown, Massachusetts 02129, USA
2Institut für Pharmakologie, Universität Bonn, D-53113 Bonn, Germany
${ }^{3}$ Cardiovascular Research Center, Massachusetts General Hospital, Harvard Medical School,
Charlestown, Massachusetts 02129, USA
${ }^{4}$ Sanders-Brown Research Center on Aging, University of Kentucky, Lexington, Kentucky 40536, USA
${ }^{5}$ Division of Experimental Medicine, Harvard Medical School, Boston, Massachusetts 02115, USA

Address correspondence to: David J. Kwiatkowski, Division of Experimental Medicine, Harvard Medical School,

221 Longwood Avenue, LMRC 312, Boston, Massachusetts 02115, USA. Phone: (617) 278-0384; Fax: (617) 734-2248;

E-mail: kwiatkowski@calvin.bwh.harvard.edu

Received for publication August 17, 1998, and accepted in revised form December 10, 1998.

\begin{abstract}
Increased $\mathrm{Ca}^{2+}$ influx through activated $N$-methyl-D-aspartate (NMDA) receptors and voltage-dependent $\mathrm{Ca}^{2+}$ channels (VDCC) is a major determinant of cell injury following brain ischemia. The activity of these channels is modulated by dynamic changes in the actin cytoskeleton, which may occur, in part, through the actions of the actin filament-severing protein gelsolin. We show that gelsolin-null neurons have enhanced cell death and rapid, sustained elevation of $\mathrm{Ca}^{2+}$ levels following glucose/oxygen deprivation, as well as augmented cytosolic $\mathrm{Ca}^{2+}$ levels in nerve terminals following depolarization in vitro. Moreover, major increases in infarct size are seen in gelsolin-null mice after reversible middle cerebral artery occlusion, compared with controls. In addition, treatment with cytochalasin D, a fungal toxin that depolymerizes actin filaments, reduced the infarct size of both gelsolin-null and control mice to the same final volume. Hence, enhancement or mimicry of gelsolin activity may be neuroprotective during stroke.
\end{abstract}

J. Clin. Invest. 103:347-354 (1999).

\section{Introduction}

$\mathrm{Ca}^{2+}$-ion homeostasis is a key determinant of neuronal injury following both acute and chronic neurodegenerative disorders, including brain ischemia (1-3). Intracellular $\mathrm{Ca}^{2+}$ overload activates several enzymes, including calpain, phospholipase, xanthine oxidase, and neuronal nitric oxide synthase, which are capable of either direct or indirect destruction of cellular structures $(1,2)$. Massive glutamate release is an early event following brain ischemia, leading to activation of $N$-methyl-D-aspartate (NMDA) receptors and voltage-dependent $\mathrm{Ca}^{2+}$ channels (VDCC), both of which mediate this excitotoxic $\mathrm{Ca}^{2+}$ influx $(1,2,4)$. Activity of these channels can be modified by dynamic changes in the actin cytoskeleton, consistent with a model in which actin filaments compartmentalize channel-regulatory proteins $(5,6)$. We demonstrated previously that actin depolymerization by the fungal toxin cytochalasin (cyto) D protects neurons from excitotoxicity by stabilizing intracellular calcium levels, $\left[\mathrm{Ca}^{2+}\right]_{\mathrm{i}}(7)$. Therefore, depolymerization of the actin microfilament network in vivo may be a promising approach to prevent neuronal death from NMDA excitotoxicity during cerebral ischemia.)

Gelsolin (gsn) is an $80-\mathrm{kDa}$ actin-binding protein and is the first and most widely expressed member of a family of actin-severing proteins, which includes adseverin and villin (8). After activation by micromolar $\mathrm{Ca}^{2+}$, gelsolin severs actin filaments, reducing actin cytoskeleton integrity, and remains bound to the barbed ends, inhibiting actin filament extension (9). Upon reduction in free $\mathrm{Ca}^{2+}$ to less than micromolar levels, and in the presence of polyphosphoinositides, gelsolin is released from the barbed ends, providing sites for rapid actin filament extension (9). Thus, gelsolin appears to serve a critical role in actin filament dynamics (10-13). Gelsolin is constitutively expressed throughout the central nervous system and is particularly concentrated in neuronal growth cones (14). We demonstrated recently that gelsolin modulates VDCC and NMDA receptor-coupled channel activity and reduces vulnerability to excitotoxicity in cultured hippocampal neurons after its activation by $\mathrm{Ca}^{2+}(15)$. In this report, we explored the possibility that gelsolin could serve as a neuroprotective factor in cerebral ischemia in response to $\left[\mathrm{Ca}^{2+}\right]_{i}$ by enhancing VDCCand NMDA-channel rundown.

\section{Methods}

Gelsolin knockout mice. Gross and microscopic anatomy of the brain of $\mathrm{gsn}^{-1-}$ mice revealed no overt abnormalities (13). Because the gelsolin-null state is not viable in either pure $\mathrm{C} 57 / \mathrm{Bl} / 6$ or BALB/C backgrounds (Witke, W., and Kwiatkowski, D. J., unpublished observations), we used gender-matched littermates from $\mathrm{gsn}^{+/-} \times \mathrm{gsn}^{+/-}$crosses in a mixed 129/SV $\times$C57BL/6 background for all in vivo experiments. In vitro experiments used littermates from $\mathrm{gsn}^{+/-} \times \mathrm{gsn}^{+/-}$crosses from both mixed 129/Sv $\times$BALB/C and $129 / \mathrm{SV} \times \mathrm{C} 57 \mathrm{BL} / 6$ backgrounds $(13,15)$. For immunoblot analyses of gelsolin cleavage, we used male wild-type 129/SVEvTacBR mice (Taconic Farms, Germantown, New York, USA). 
Table 1

Physiologic variables in gelsolin-null and wild-type littermate mice

\begin{tabular}{|c|c|c|}
\hline Parameter & $\mathrm{gsn}^{+/+}$ & $\mathrm{gsn}^{-/-}$ \\
\hline \multicolumn{3}{|c|}{$\mathrm{MABP}(\mathrm{mmHg})$} \\
\hline Baseline & $88 \pm 2$ & $87 \pm 2$ \\
\hline During & $92 \pm 2$ & $89 \pm 1$ \\
\hline After & $89 \pm 4$ & $91 \pm 4$ \\
\hline \multicolumn{3}{|l|}{$\mathrm{pH}$} \\
\hline Baseline & $7.39 \pm 0.01$ & $7.37 \pm 0.03$ \\
\hline After & $7.34 \pm 0.02$ & $7.34 \pm 0.01$ \\
\hline \multicolumn{3}{|l|}{$\mathrm{PaO}_{2}(\mathrm{mmHg})$} \\
\hline Baseline & $172 \pm 9$ & $162 \pm 16$ \\
\hline After & $130 \pm 13$ & $129 \pm 10$ \\
\hline \multicolumn{3}{|c|}{$\mathrm{PaCO}_{2}(\mathrm{mmHg})$} \\
\hline Baseline & $40 \pm 2$ & $42 \pm 2$ \\
\hline After & $41 \pm 1$ & $42 \pm 1$ \\
\hline \multicolumn{3}{|l|}{ rCBF (\%) } \\
\hline Before & $100 \pm 0$ & $100 \pm 0$ \\
\hline During & $13 \pm 2$ & $13 \pm 3$ \\
\hline After & $88 \pm 8$ & $91 \pm 11$ \\
\hline Weight (g) & $25.3 \pm 1.0$ & $24.4 \pm 1.1$ \\
\hline \multicolumn{3}{|l|}{$\mathrm{CT}\left({ }^{\circ} \mathrm{C}\right)$} \\
\hline During & $36.8 \pm 0.1$ & $36.9 \pm 0.1$ \\
\hline
\end{tabular}

Animals were subjected to $2 \mathrm{~h}$ of filamentous middle cerebral artery occlusion followed by reperfusion $(22,24,25)$. MABP and $\mathrm{rCBF}$ were measured at baseline, during ischemia, and $30 \mathrm{~min}$ after reperfusion $(22,24,25)$. Before ischemia and directly after reperfusion, $50 \mathrm{ml}$ of blood was withdrawn for blood gas determination $\left(\mathrm{pH}, \mathrm{PaO}_{2}, \mathrm{PaCO}_{2}\right)$. Animals were weighed before the onset of the experiment (body weight in grams). CT was controlled and recorded by means of a feedback temperature control unit. There were no statistically significant differences between groups in any of the parameters studied ( $n=6$ animals each group). ANOVA and Scheffe's test. $C T$, core temperature; gsn, gelsolin; $M A B P$, mean arterial blood pressure; $r C B F$, regional cerebral blood flow.

Glucose/oxygen deprivation in hippocampal cell cultures. Hippocampal cell cultures were established from 18-day-old embryos as described previously $(15,16)$. Hippocampi from each embryo were dissociated by trypsinization and trituration and plated into culture dishes; DNA from the body of each embryo was isolated and used for PCR-based genotyping. Experiments were performed in a blinded fashion. Cells were grown in polyethylenimine-coated plastic or glass bottom 35-mm culture dishes containing Eagle's MEM supplemented with $10 \%$ (vol/vol) heat-inactivated FBS, 20 $\mathrm{mM} \mathrm{KCl}$, and $1 \mathrm{mM}$ pyruvate. Atmosphere consisted of $6 \%$ $\mathrm{CO}_{2} / 94 \%$ room air and was maintained near saturation. Cells were exposed to $30 \mathrm{~min}$ of glucose and oxygen (G/O) deprivation as described previously (15). For controls, medium was changed without G/O deprivation. Cultures were then incubated for an additional $20 \mathrm{~h}$ in Locke's solution, and neuronal survival was quantified using a method that has been shown to correlate closely with trypan-blue staining $(7,16,17)$. Briefly, neuronal viability was assessed by morphological criteria: cells with intact neurites of uniform diameter and a soma with a smooth round appearance were considered viable, whereas neurons with fragmented neurites and a vacuolated or swollen soma were considered nonviable. Analyses were made in a blinded fashion.

Calcium imaging methods. Intracellular free $\mathrm{Ca}^{2+}$ levels were quantified by ratiometric imaging of the fluorescent calcium indicator dye fura-2 (Molecular Probes Inc., Eugene, Oregon, USA) as described (18). Briefly, cells were loaded with the acetoxymethylester form of fura-2 (30-min incubation in the presence of $10 \mathrm{mM}$ fura-2/AM), and imaging was performed using a Zeiss AttoFluor system with a $40 \times$ oil objective. The average $\left[\mathrm{Ca}^{2+}\right]_{\mathrm{i}}$ in individual neuronal cell bodies was determined from the ratio of the fluorescence emissions obtained using two different excitation wavelengths ( 334 and $380 \mathrm{~nm}$ ). The system was calibrated with solutions containing either no $\mathrm{Ca}^{2+}$ or a saturating level of $\mathrm{Ca}^{2+}(1 \mathrm{mM})$ using the formula $\left[\mathrm{Ca}^{2+}\right]_{\mathrm{i}}=K_{\mathrm{d}}[(R-$ $\left.\left.R_{\min }\right) / R_{\max }-R_{0}\left(F_{0} / F_{s}\right)\right](19)$.

$\left[\mathrm{Ca}^{2+}\right]_{i}$ measurement in synaptosomes. Synaptosomes (torn-off and resealed nerve terminals) were prepared from $\mathrm{gsn}^{+/+}$or $\mathrm{gsn}^{-/-}$mice according to Gleitz et al. (20), with slight modifications. Briefly, cerebral cortices were homogenized with a Potter-Elvehjem glass homogenizer $(900 \mathrm{rpm})$ in $40 \mathrm{vol}(\mathrm{wt} / \mathrm{vol})$ of $0.32 \mathrm{M}$ sucrose. The homogenate was centrifuged ( $10 \mathrm{~min}$, $1,000 \mathrm{~g}$ at $4^{\circ} \mathrm{C}$ ), and the supernatant was frozen and stored at $-80^{\circ} \mathrm{C}$. After thawing at $37^{\circ} \mathrm{C}$, the supernatant was centrifuged $\left(10 \mathrm{~min}, 12,000 \mathrm{~g}\right.$ at $\left.4^{\circ} \mathrm{C}\right)$, and the synaptosomal pellet was resuspended in a $\mathrm{Ca}^{2+}$-free buffer ( $\mathrm{pH}$ 7.4) containing $133 \mathrm{mM} \mathrm{NaCl}, 4.8 \mathrm{mM} \mathrm{KCl}, 10 \mathrm{mM}$ HEPES, $1.2 \mathrm{mM}$ $\mathrm{Na}_{2} \mathrm{HPO}_{4}, 1.2 \mathrm{mM} \mathrm{MgSO}_{4}$, and $10 \mathrm{mM}$ glucose. $\left[\mathrm{Ca}^{2+}\right]_{\mathrm{i}}$ was measured by a fluorescence ratiometric method according to Grynkiewicz et al. (19) and Meder et al. (21) using a PerkinElmer LS 50B spectrofluorometer $\left(\lambda_{\text {ex }}=340 / 380 \mathrm{~nm}, \lambda_{\text {em }}=510\right.$ $\mathrm{nm})$. The synaptosomal suspension was incubated with fura2/AM $(5 \mu \mathrm{M})$ for $35 \mathrm{~min}$ at $37^{\circ} \mathrm{C}$. Fura-2-loaded synaptosomes were washed and kept on ice until they were used. Aliquots $(200 \mu \mathrm{l})$ of the washed synaptosomal suspension containing $136 \pm 7 \mu \mathrm{g} / \mathrm{ml}$ of protein were diluted with $1.8 \mathrm{ml} \mathrm{Ca}^{2+}$ free buffer (as above) plus $1.3 \mathrm{mM} \mathrm{CaCl}_{2}$. The diluted samples were placed in a quartz cuvette at $37^{\circ} \mathrm{C}$ and preincubated for 6 min before $\mathrm{K}^{+}(30 \mathrm{mM})$ was added for depolarization. The system was calibrated with Triton X-100 for maximum $\mathrm{Ca}^{2+}$ concentrations and with EGTA for minimum $\mathrm{Ca}^{2+}$ concentrations. $\left[\mathrm{Ca}^{2+}\right]_{\mathrm{i}}$ was calculated as above (19).

Drug administration. Cyto D (Aldrich Chemical Co., Milwaukee, Wisconsin, USA) was dissolved in 1\% DMSO in PBS. Then, $2 \mu \mathrm{l}$ of the solution or vehicle was administered intracerebroventricularly (bregma $-0.9 \mathrm{~mm}$ lateral, $-0.1 \mathrm{~mm}$ posterior, -3.1-mm deep) $10 \mathrm{~min}$ before ischemia using a Hamilton syringe (Fisher Scientific Co., Pittsburgh, Pennsylvania, USA) as described $(22,23)$.

Mouse model of focal cerebral ischemia. All animal experiments were conducted in accordance with National Institutes of Health and institutional guidelines. Mice (18-23 g) were anesthetized with $1.5 \%$ halothane (induction) and maintained on $1.0 \%$ halothane in $70 \%$ nitrous oxide and $30 \%$ oxygen by face mask. Regional cerebral blood flow (rCBF) was measured by Laser-Doppler monitoring using a flexible skull probe as described $(22,24,25)$. In randomly selected animals, the left femoral artery was cannulated for arterial blood pressure and blood gas determination as described $(22,24,25)$. Arterial blood samples $(50 \mu \mathrm{l})$ were analyzed for $\mathrm{pH}$, arterial oxygen pressure $\left(\mathrm{PaO}_{2}\right)$, and partial pressure of carbon dioxide $\left(\mathrm{PaCO}_{2}\right)$ using a Ciba-Corning $248 \mathrm{PH} /$ blood gas analyzer (Ciba-Corning Diagnostics, Corp. Medfield, Massachusetts, USA). Focal cerebral ischemia was induced by introducing a silicone-coated 8-0 monofilament into the internal carotid artery and advancing it $(22,24,25)$. By so doing, the middle cerebral artery was occluded. Two hours later, the filament was completely withdrawn to allow reperfusion. Rectal temperature was controlled and maintained at $\sim 37^{\circ} \mathrm{C}$ with a temperature feedbackcontrol unit (Frederick Haer and Co., Brunswick, Maine, USA) and a heating lamp during the monitoring period until $1 \mathrm{~h}$ after reperfusion. No differences in rectal temperatures were observed between groups during the monitoring period and after $24 \mathrm{~h}$. Moreover, when we determined temporalis muscle temperature for up to $2 \mathrm{~h}$, and again after $24 \mathrm{~h}$, we did not observe any significant changes between groups (gsn-null mice and cyto D-treated mice $)$ at any time $\left(< \pm 0.3^{\circ} \mathrm{C}, P>0.05\right)$. 


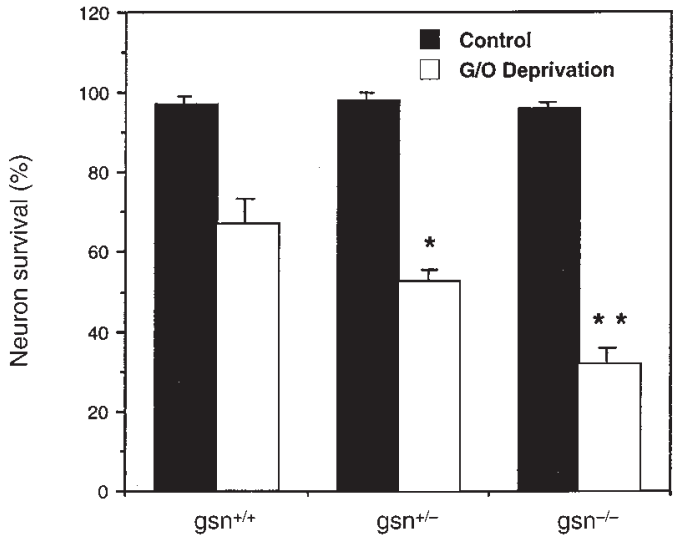

Figure 1

Neuronal vulnerability to combined glucose and oxygen deprivation is increased in hippocampal neurons lacking gelsolin (gsn). Cultures from $\mathrm{gsn}^{+/+}, \mathrm{gsn}^{+/-}$, and $\mathrm{gsn}^{-/-}$mice were subjected to combined G/O deprivation or medium change without $\mathrm{G} / \mathrm{O}$ deprivation (control) for $30 \mathrm{~min}$. Cultures were then incubated for an additional $20 \mathrm{~h}$ in Locke's solution and neuronal survival was quantified. Values are the mean and SE of determinations made in four separate cultures. ${ }^{*} P<0.05$ compared with the value in $\mathrm{gsn}^{+/+}$cultures exposed to $\mathrm{G} / \mathrm{O}$ deprivation. ${ }^{*} P<0.01$ compared with value in $\mathrm{gsn}^{+/+}$cultures exposed to $\mathrm{G} / \mathrm{O}$ deprivation, and $P<0.05$ compared with the value in gsn ${ }^{+/-}$cultures exposed to $\mathrm{G} / \mathrm{O}$ deprivation. ANOVA followed by Scheffe's post hoc tests. G/O, glucose/oxygen.

Neurological deficits. Mice were tested for neurological deficits $30 \mathrm{~min}$ and $24 \mathrm{~h}$ after induction of ischemia and rated on a scale from 0 (no observable deficit) to 3 (severe) $(22,24,25)$. Briefly, failure to extend the forepaw when suspended vertically is graded as mild injury [1], circling to the contralateral side is graded as moderate [2], and loss of circling or righting reflex is graded as severe [3]. Animals were graded by an observer blinded to group identity.

Determination of infarct size. The animals were sacrificed $22 \mathrm{~h}$ or $70 \mathrm{~h}$ after reperfusion. The brains were snap-frozen in isopentane for cryostat sectioning or directly divided into five coronal 2-mm sections using a brain matrix (RBM-2000C; Activational Systems, Ann Arbor, Michigan, USA). Infarction areas were quantitated with MCID M4 image analysis software (Imaging Research Inc., St. Catharine's, Ontario, Canada) on 2\% 2,3,5 triphenyltetrazoliumchloride-stained $2-\mathrm{mm}$ slices (cyto D experiments with $22 \mathrm{~h}$ of reperfusion) or on $20-\mu \mathrm{m}$ hematoxylin-and eosin-stained cryostat sections (all gsn experiments and cyto D experiments with $70 \mathrm{~h}$ of reperfusion). Infarction volume was calculated by summing the volumes of each section directly (25) or indirectly using the following formula: contralateral hemisphere $\left(\mathrm{mm}^{3}\right)$ - undamaged ipsilateral hemisphere $\left(\mathrm{mm}^{3}\right)$ (26). The difference between direct and indirect infarct volumes is likely to be accounted for by brain swelling.

Gelsolin Western blotting. After $2 \mathrm{~h}$ of middle cerebral artery (MCA) occlusion and varying times of reperfusion, animals were injected with $200 \mathrm{mg} / \mathrm{kg}$ pentobarbital intraperitoneally and transcardially perfused with ice-cold PBS (pH 7.4). Subsequently, brains were cut into $2-\mathrm{mm}$ slices with a brain matrix and placed on a chilled glass plate. Using a dissecting microscope, tissue from the ischemic MCA territory was isolated and snapfrozen in liquid nitrogen along with tissue from corresponding brain regions in the contralateral hemisphere. Samples were stored at $-80^{\circ} \mathrm{C}$ until used. Tissue was homogenized in $10 \mathrm{mM}$ HEPES buffer ( $\mathrm{pH}$ 7.6) containing $5 \mathrm{mM} \mathrm{MgCl}_{2}, 1 \mathrm{mM}$ PMSF, $1.5 \mu \mathrm{M}$ pepstatin, $2 \mu \mathrm{M}$ leupeptin, $0.7 \mu \mathrm{M}$ aprotinin, $10 \mu \mathrm{M} \mathrm{N}$ benzyloxycarbonyl-Asp-Glu-Val-Asp-CHO (DEVD-CHO; En- zyme System Products, Dublin, California, USA), centrifuged at $50,000 \mathrm{~g}$ for $30 \mathrm{~min}$, and the supernatant was kept at $-80^{\circ} \mathrm{C}$ until used. Then, $10 \mu \mathrm{g}$ total protein per sample was subjected to SDSPAGE and transferred to a polyvinylidene fluoride (PVDF) membrane (Millipore Corp., Bedford, Massachusetts, USA). Blots were blocked with 5\% nonfat milk in TBST (50 mM Tris, [pH 7.5], 150 $\mathrm{mM} \mathrm{NaCl}, 0.05 \%$ Tween- 20 ) overnight at $4{ }^{\circ} \mathrm{C}$ and probed with polyclonal gelsolin antiserum at a dilution of 1:10,000 in 5\% nonfat milk/TBST as described (27). Immunoblots were then processed with horseradish peroxidase-conjugated anti-rabbit IgG and detected using the enhanced chemiluminescence (ECL) Western blotting detection system kit (Amersham Life Sciences Inc., Arlington Heights, Illinois, USA).

Immunobistochemical staining for calpain-cleaved spectrin, microtubule-associated protein-2, and IgG. Calpain is activated by intracellular $\mathrm{Ca}^{2+}$ and, in turn, cleaves the cytoskeletal protein spectrin. $\mathrm{Ca}^{2+}$ also causes microtubule-associated protein (MAP)-2 proteolysis. Analyses of spectrin-breakdown products and loss of MAP2 immunoreactivity therefore can be used as in vivo measures of $\mathrm{Ca}^{2+}$-mediated cell damage. To do so, we performed immunohistochemistry to stain calpain-cleaved spectrin and MAP-2. To evaluate for disruption of the blood-brain barrier, immunohistochemical staining for $\operatorname{IgG}$ was performed. Gsn ${ }^{-/}$and $\mathrm{gsn}^{+/+}$mice underwent occlusion of the middle cerebral artery for $2 \mathrm{~h}$ as described (four to five animals per group per time period). The rCBF was monitored in all animals. After $1 \mathrm{~h}$ or $4 \mathrm{~h}$ of reperfusion, animals were sacrificed and immediately perfused transcardially with $4 \%$ paraformaldehyde. After removal, brains were immersed in $4 \%$ paraformaldehyde. Immunohistochemistry was performed in free-floating sections using methods described previously (28). Sections were incubated for $2 \mathrm{~h}$ at room temperature in a solution containing Triton X-100 and $0.015 \%$ blocking serum (normal goat serum) in PBS. Primary antibody was then added to a final dilution of either 1:10,000 for the spectrin antibody or 1:5,000 for the MAP-2 antibody, and sections were then incubated overnight at $4^{\circ} \mathrm{C}$. Sections were incubated in the presence of horse

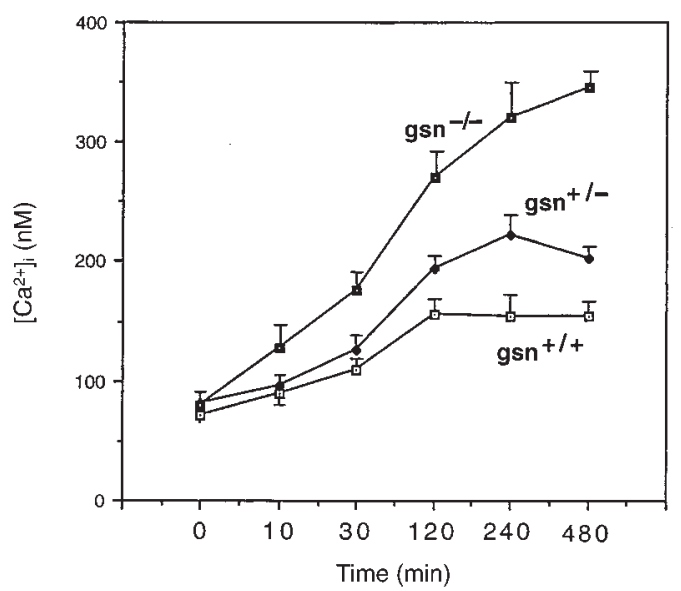

Figure 2

Elevation of intracellular $\mathrm{Ca}^{2+}$ levels following combined glucose and oxygen deprivation is enhanced in hippocampal neurons lacking gelsolin (gsn). Cells from $\mathrm{gsn}^{+/+}, \mathrm{gsn}^{+/-}$, and $\mathrm{gsn}^{-/-}$mice were loaded with fura-2 and then subjected to combined $\mathrm{G} / \mathrm{O}$ deprivation or medium change without $\mathrm{G} / \mathrm{O}$ deprivation (control) for $30 \mathrm{~min}$. The $\left[\mathrm{Ca}^{2+}\right]_{\mathrm{i}}$ in individual neuronal cell bodies was then quantified at the indicated time points by fluorescence ratio imaging. Values are the mean and SE of determinations made in three separate cultures (15-25 neurons analyzed per culture). $\left[\mathrm{Ca}^{2+}\right]_{\mathrm{i}}$ values for $\mathrm{gsn}^{-/-}$neurons were significantly greater than values for $\mathrm{gsn}^{+/+}$and $\mathrm{gsn}^{+/-}$neurons at $30 \mathrm{~min}(P<0.05)$ and 120, 240, and 480 $\min (P<0.01$ in each case). ANOVA followed by Scheffe's post hoc tests. $\left[\mathrm{Ca}^{2+}\right]_{i}$, intracellular calcium. 


\section{Figure 3}

Infarct size in $\mathrm{gsn}^{+/+}$and $\mathrm{gsn}^{-/-}$mice after MCA occlusion/reperfusion. Infarct size was 45\% larger in gsn ${ }^{-/-}$mice compared with wild-type gsn ${ }^{+/+}$ littermate mice $22 \mathrm{~h}$ after $2 \mathrm{~h}$ of filamentous MCA occlusion. (a) Brain infarct volume and $(\boldsymbol{b})$ brain infarct area (2-mm coronal sections) were determined as described previously $(22,24,25)$ and were increased in $\mathrm{gsn}^{-/-}$mice (open triangles) compared with $\mathrm{gsn}^{+/+}$mice (filled squares). Infarcts were also larger after correcting for brain swelling by an indirect method to measure infarct size (26). Data are presented as mean and SE. $n=10$ animals per group. ${ }^{*} P<0.05$ and ${ }^{*} P<0.01$ compared with wild-type. Student's $t$ test. MCA, middle cerebral artery.

anti-mouse IgG to detect the presence of endogenous immunoglobulin in brain parenchyma. Sections were then incubated for $1 \mathrm{~h}$ in $\mathrm{ABC}$ reagent (Vector Laboratories, Burlingame, California, USA), washed in PBS, and incubated for $5 \mathrm{~min}$ in diaminobenzidine solution (Vector Laboratories). The primary antibodies were rabbit polyclonal antibodies specific for a calpaincleavage product of spectrin (a generous gift from R. Siman, Cephalon Inc. West Chester, Pennsylvania, USA) and against MAP-2 (a generous gift from S. Halpain, The Scripps Research Institute, La Jolla, California, USA). Brain sections were photographed under bright-field optics using a $1 \times$ objective.

Data analysis. Values are presented as mean \pm SE. Statistical comparisons were performed by unpaired Student's $t$ test or ANOVA followed by Student's $t$ test, Scheffe's test, or Tukey's test as indicated. For comparisons of neurological deficits, a nonparametric test (Mann-Whitney rank sum test) was used. $P<0.05$ was considered significant.

\section{Results}

Neuronal survival is reduced and intracellular $\mathrm{Ca}^{2+}$ levels elevated after glucose and oxygen deprivation in hippocampal neurons lacking gelsolin. Primary cultures of hippocampal neurons were established from E18 gelsolin-null embryos. When these cells were exposed to combined glucose and oxygen (G/O) deprivation, we found that $\mathrm{gsn}^{-/}$cells were significantly more vulnerable than $\mathrm{gsn}^{+/+}$cells (Fig. 1). Gsn ${ }^{+/-}$neurons exhibited a level of intermediate vulnerability (Fig. 1).

To test whether enhanced susceptibility to glucose and oxygen deprivation is correlated with increased intracellular $\mathrm{Ca}^{2+}$ levels $\left(\left[\mathrm{Ca}^{2+}\right]_{\mathrm{i}}\right)$ in $\mathrm{gsn}^{-/-}$cells, $\left[\mathrm{Ca}^{2+}\right]_{\mathrm{i}}$ was assessed using the indicator dye fura-2. Basal $\left[\mathrm{Ca}^{2+}\right]$ i was essentially identical in neurons of all three genotypes $(\sim 120 \mathrm{nM})(15)$. When cells were subjected to combined $\mathrm{G} / \mathrm{O}$ deprivation, $\mathrm{gsn}^{-/-}$cells, and in an intermediate fashion $\mathrm{gsn}^{+/-}$cells, showed a more rapid and sustained $\left[\mathrm{Ca}^{2+}\right]_{\mathrm{i}}$ increase compared with gsn ${ }^{+/+}$cells (Fig. 2). Hence, the greater susceptibility to $\mathrm{G} / \mathrm{O}$ deprivation in $\mathrm{gsn}^{-/}$ cells may be mediated, at least in part, by $\left[\mathrm{Ca}^{2+}\right]_{\mathrm{i}}$.

Tissue injury following brain ischemia is increased in gsn-1mice. G/O deprivation and glutamate neurotoxicity are common models for studying mechanisms of vascular stroke injury in vitro. Because neurons from $\mathrm{gsn}^{-/-}$mice exhibited higher susceptibility to these insults, we tested the effects of gelsolin gene deletion in a model of reversible focal brain ischemia in vivo. Animals were subjected to two hours of MCA occlusion using a silicone-coated 8-0 monofilament, followed by 22 hours of reperfusion. Infarcts were $45 \%$ bigger in $\mathrm{gsn}^{-/-}$mice, compared with controls (Fig. 3). Brain swelling contributed partly to the larger infarcts in $\mathrm{gsn}^{-/-}$mice (40.6

\section{a}
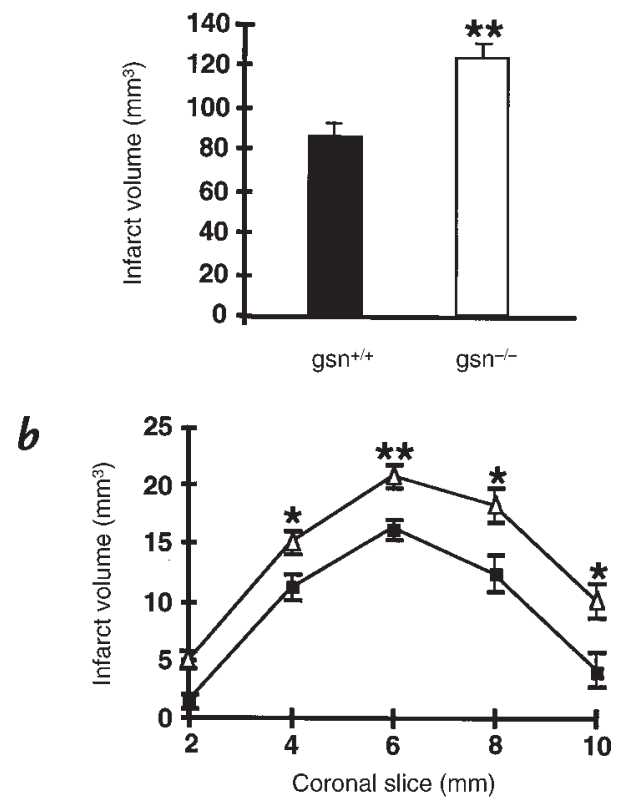

$\pm 7.7 \mathrm{~mm}^{3}$ vs. $25.0 \pm 6.1 \mathrm{~mm}^{3}$ in $\mathrm{gsn}^{-/-}$vs. $\mathrm{gsn}^{+/+}$, respectively). When infarction volume was corrected for brain swelling (calculated with the indirect method), infarcts in $\mathrm{gsn}^{-/}$mice were still enlarged by $36 \%\left(82.9 \pm 6.5 \mathrm{~mm}^{3}\right.$ vs. $60.4 \pm 4.9 \mathrm{~mm}^{3}$ in $\mathrm{gsn}^{-/-}$vs. gsn ${ }^{+/+}$, respectively; $P<$ $0.05)$. Significantly larger lesions were evident in four of the five standardized coronal brain sections (Fig. 3).

Because there is a secreted form of gelsolin (10), we looked for changes in cerebral blood flow during ischemia and after reperfusion that might modify infarct volume. To evaluate if differences in brain perfusion contributed to the higher susceptibility to injury in $\mathrm{gsn}^{-/-}$ mice, rCBF was determined using Laser-Doppler moni-

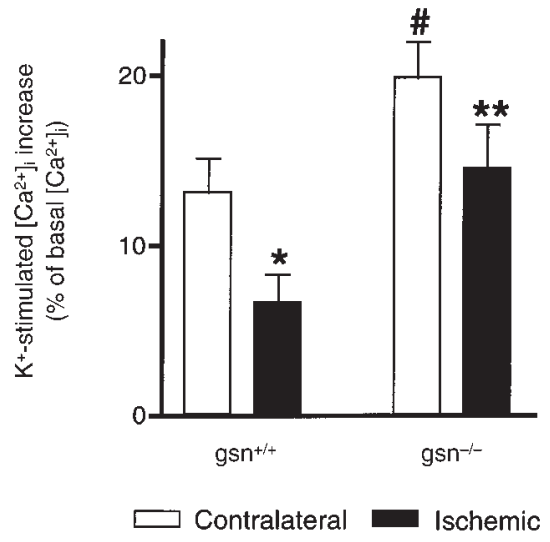

Figure 4

Effect of ischemia on $\mathrm{K}^{+}(30 \mathrm{mM})$-induced increase in $\left[\mathrm{Ca}^{2+}\right]_{i}$ in synaptosomes prepared from mice deficient for gelsolin $\left(\mathrm{gsn}^{-/-}\right)$compared with wild-type $\left(g^{S n^{+/+}}\right)$. Synaptosomes were prepared from contralateral cortex (open bars) and ischemic cortex (filled bars) after $2 \mathrm{~h}$ ischemia and $1 \mathrm{~h}$ of reperfusion. Cytosolic $\mathrm{Ca}^{2+}$ concentrations were determined ratiometrically using the fluorescent calcium indicator dye fura-2/AM. Increase in $\left[\mathrm{Ca}^{2+}\right]_{i}$ is presented as percent of basal $\left[\mathrm{Ca}^{2+}\right]_{\mathrm{i}}$. Data are the mean $\pm \mathrm{SE}$ of three to four experiments in duplicate. ${ }^{*} P<0.05$ vs. gsn ${ }^{+/+}$contralateral, ${ }^{\#} P<0.05$ vs. gsn ${ }^{+/+}$contralateral, ${ }^{*} P<0.05$ vs. gsn ${ }^{+/+}$ischemic. ANOVA followed by Student's $t$ test . 
Figure 5

Evidence for increased $\mathrm{Ca}^{2+}$-mediated proteolysis following MCA occlusion/reperfusion in $\mathrm{gsn}^{-/-}$mice. Gsn ${ }^{+/+}$and $\mathrm{gsn}^{-/-}$mice were subjected to 2 $\mathrm{h}$ MCA occlusion and were sacrificed $1 \mathrm{~h}$ after reperfusion. Coronal brain sections were immunostained with antibodies against calpain-cleaved spectrin and MAP-2; additional sections were reacted with biotinylated horse anti-mouse IgG (upper panels). Note increased IgG immunoreactivity, increased spectrin immunoreactivity, and decreased MAP-2 immunoreactivity in the $\mathrm{gsn}^{-/-}$mice. These micrographs are representative of five $\mathrm{gsn}^{-/}$ and four $\mathrm{gsn}^{+/+}$mice examined. MAP-2, mitogen-activated protein-2.

toring. We found that rCBF fell to less than $20 \%$ of baseline during ischemia and returned to $\sim 90 \%$ within five minutes after reperfusion without differences between groups (Table 1). Arterial blood pressure, blood gases $\left(\mathrm{pH}, \mathrm{PaO}_{2}\right.$, and $\left.\mathrm{PaCO}_{2}\right)$, and core temperature during ischemia and reperfusion also were not different between groups (Table 1). Taken together, it seems unlikely that variations in brain perfusion or systemic physiologic parameters contributed to the susceptibility to injury in $\mathrm{gsn}^{-/-}$mice.

Increased cytosolic $\mathrm{Ca}^{2+}$ concentrations in cortical nerve terminals from gsn ${ }^{-1-}$ mice after depolarization and after ischemia. Because glutamate released via exocytosis from presynaptic terminals during ischemia is dependent on $\mathrm{Ca}^{2+}$ influx, we studied cytosolic $\mathrm{Ca}^{2+}$ concentration in synaptosomes isolated from ischemic and normal contralateral cortex. Basal $\mathrm{Ca}^{2+}$-concentrations in nerve terminals did not differ between $\mathrm{gsn}^{+/+}$and gsn ${ }^{-/-}$(290 \pm 60 and 299 $\pm 33 \mathrm{nM}$, respectively). However, depolarization (30 mM $\left.\mathrm{K}^{+}\right)$-induced VDCC-mediated increases in $\left[\mathrm{Ca}^{2+}\right]_{\text {i }}$ were higher in $\mathrm{gsn}^{-/-}$compared with gsn $\mathrm{H}^{+/+}$synaptosomes (Fig. 4). After two hours ischemia followed by one hour of reperfusion, depolarization by $30 \mathrm{mM} \mathrm{K}^{+}$also produced a substantially higher $\left[\mathrm{Ca}^{2+}\right]_{\mathrm{i}}$ increase in $\mathrm{gsn}^{-/}$compared with $\mathrm{gsn}^{+/+}$synaptosomes (Fig. 4). Basal $\left[\mathrm{Ca}^{2+}\right]_{\mathrm{i}}$ was reduced following ischemia in $\mathrm{gsn}^{+/+}$and $\mathrm{gsn}^{-/-}$synaptosomes $(220 \pm 9$ and $212 \pm 18 \mathrm{nM}$, respectively), probably due to a reduced number of functionally intact terminals. Higher ischemia-induced $\left[\mathrm{Ca}^{2+}\right]_{i}$ suggest that functional alterations in VDCC may contribute to the greater susceptibility of $\mathrm{gsn}^{-/-}$mice to cerebral ischemia.

Ischemia-induced cytoskeletal alterations associated with calcium influx are exacerbated in mice lacking gelsolin. Previous studies have shown that $\mathrm{Ca}^{2+}$-mediated proteolysis of cytoskeletal proteins such as spectrin and MAP-2 occurs during the first few hours after ischemia/reperfusion and correlates closely with subsequent neuronal degeneration and death $(29,30,31)$. Because our data indicated that $\mathrm{Ca}^{2+}$ influx through $N$-methyl-D-aspartate NMDA receptors and VDCC is enhanced in neurons lacking gelsolin, we performed immunohistochemical analyses to assess the development of $\mathrm{Ca}^{2+}$-mediated proteolysis

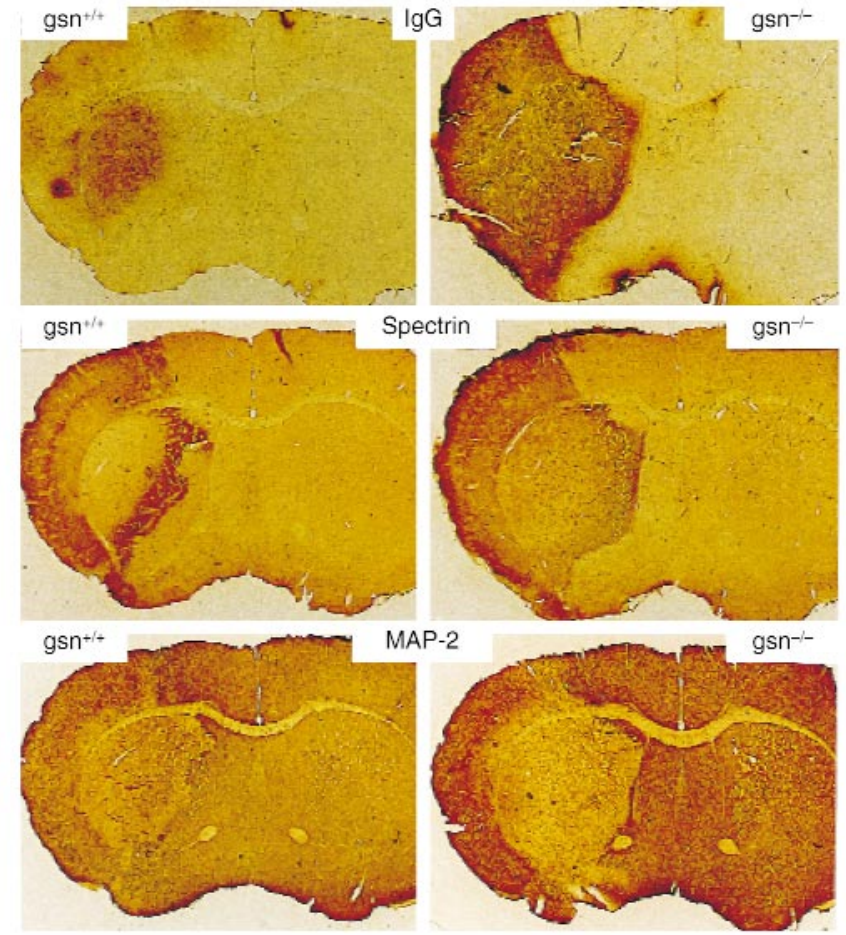

following MCA occlusion in gsn ${ }^{+/+}$and gsn-/- mice. Compared with $\mathrm{gsn}^{+/+}$mice, the extent of calpain-mediated spectrin proteolysis, as assessed with an antibody against calpain-cleaved spectrin (Ab37) (29), was greater in striatum and cortex of gsn ${ }^{-/}$mice (Fig. 5). Increased spectrin proteolysis in gsn ${ }^{-/}$was accompanied by decreased MAP2 immunoreactivity, consistent with $\mathrm{Ca}^{2+}$-mediated proteolysis of this protein, as well (Fig. 5). Previous studies have shown a strong correlation between infarct volume and disruption of the blood-brain barrier following MCA occlusion/reperfusion. Moreover, NMDA receptor antagonists reduce the extent of blood-brain barrier disruption,

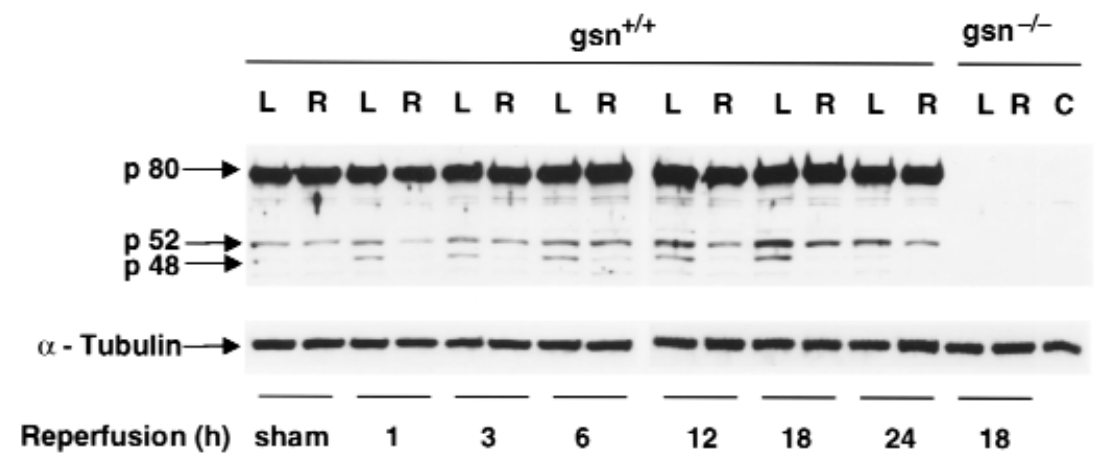

\section{Figure 6}

Time-dependent changes in gelsolin protein and cleavage product expression during reperfusion following $2 \mathrm{~h} \mathrm{MCA}$ occlusion in brain lysates from normal $\left(\mathrm{gsn}^{+/+}\right)$or gelsolin knockout $\left(\mathrm{gsn}^{-/-}\right)$mice. Brain lysates $(10 \mu \mathrm{g} / \mathrm{lane})$ were subjected to SDS-PAGE and immunoblot analysis using a polyclonal gelsolin antibody (ref. 27). Uncleaved gelsolin ( $80 \mathrm{kDa})$ was present in normal brain (sham) and did not change over time when measured in five different experiments. Cleavage product ( $\mathrm{p} 48$ ) was increased $1-18 \mathrm{~h}$ after reperfusion in the left ( $L$, ischemic) compared with the right ( $R$, contralateral) hemisphere. A $52-\mathrm{kDa}$ cleavage product was present in all samples including sham but was increased in ischemic hemispheres. Gsn ${ }^{-/-}$mice lack gelsolin in hemispheres $(L$ and $R$ ) and cerebellum $(C)$. $\alpha$-tubulin was used as an internal control. The experiment was repeated five times; a representative experiment is shown. 
Figure 7

Infarct size and neurological deficits after cytochalasin D (cyto D) treatment following MCA occlusion/reperfusion. (a) Treatment with the actin-depolymerizing compound cyto D $(0.1$ and $1.0 \mu \mathrm{g}$ intracerebroventricularly 10 $\mathrm{min}$ before ischemia) reduced infarct size after $2 \mathrm{~h}$ of filamentous MCA occlusion and $22 \mathrm{~h}$ of reperfusion compared with vehicle in 129/SV mice. Cerebral infarction volume was determined quantitatively as described; significant differences were also obtained when infarct sizes were corrected for brain swelling. Data are presented as mean and SE $(n=8-12$ animals per group). ${ }^{*} P<0.05$ vs. vehicle. Student's $t$ test. (b) Neurological sensory-motor deficits were significantly reduced in cyto D-treated 129/SV mice compared with controls. Deficits were evaluated blindly using an established rating system from 0 (no deficit) to 3 (severe). Data are presented as mean and SE ( $n=8-12$ animals per group). ${ }^{*} P<0.05$ vs. vehicle. MannWhitney rank sum test.

suggesting a role for NMDA receptors in this process (32-34). Consistent with the latter findings, the extent of IgG accumulation in brain parenchyma was strikingly greater in $\mathrm{gsn}^{-/-}$mice compared with gsn ${ }^{+/+}$mice (Fig. 5). Collectively, these data are consistent with enhanced $\mathrm{Ca}^{2+}$ influx through NMDA receptors and VDCC in cortical and striatal neurons following MCA occlusion/reperfusion in mice lacking gelsolin.

Gelsolin undergoes cleavage after cerebral ische-mia/reperfusion. Because we have recently demonstrated that gelsolin is cleaved by caspase- 3 during apoptosis (27) and that caspase- 3 is activated following cerebral ischemia (35), we characterized the fate of gelsolin after ischemia/reperfusion in wild-type mice. Immunoblot analysis of brain lysates from $129 / \mathrm{SV}$ mice after two hours of ischemia and reperfusion (0-24 hours) demonstrated gelsolin fragments at $1,3,6,9,12$, and 18 hours after reperfusion (Fig. 6). The gelsolin fragments measured $48 \mathrm{kDa}$ and 52 $\mathrm{kDa}$, respectively, as we have seen previously (35). Hence, gelsolin is cleaved, presumably by caspase-3; however, this event seems unlikely to account for the larger infarct size in the gelsolin-null mice.

Actin depolymerization by cyto D protects wild-type mice from vascular injury. To test the theory that dynamic changes in the actin cytoskeleton are responsible for differences in ischemic outcome between $\mathrm{gsn}^{-/-}$and $\mathrm{gsn}^{+/+}$mice, we treated wild-type 129/SV mice with the actin-depolymerizing fungal toxin cyto D. Mice were injected intracerebroventricularly with cyto D 10 minutes before two hours of MCA occlusion, followed by 22 hours of reperfusion. Intracerebroventricular injections with cyto D had no obvious effects on rectal or temporalis muscle temperatures (see Methods). Mice treated with 0.1 or $1.0 \mu \mathrm{g}$ cyto $\mathrm{D}$ intracerebroventricularly exhibited significantly smaller cerebral infarcts compared with vehicle-injected controls (Fig. 7a). This effect was also significant when measured with an indirect method to obviate the impact of brain edema on outcome $\left(77.2 \pm 8.0 \mathrm{~mm}^{3}\right.$ vs. $47.7 \pm 9.1$ $\mathrm{mm}^{3}$ for vehicle vs. $1.0 \mu \mathrm{g}$, and $79.7 \pm 6.8 \mathrm{~mm}^{3}$ vs. $54.1 \pm$ $7.5 \mathrm{~mm}^{3}$ for vehicle vs. $0.1 \mathrm{mg} ; P<0.05$ vs. vehicle for either treatment). Moreover, functional neurological deficits were significantly improved after $1.0 \mu \mathrm{g}$ cyto D and showed a trend toward lower scores with the 0.1-mg dose, indicating that infarct sparing may be accompanied by functional improvements (Fig. $7 b$ ). The protective effect after a single dose of cyto D $(1.0 \mu \mathrm{g}$ given $10 \mathrm{~min}-$ a

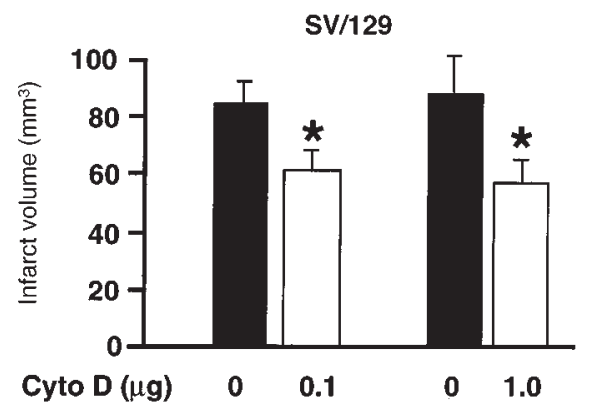

$\boldsymbol{b}$

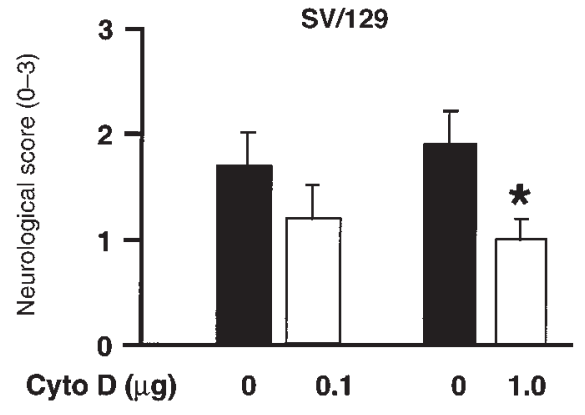

utes before two hours of MCA occlusion) was sustained for at least three days $\left(135 \pm 11 \mathrm{~mm}^{3}\right.$ vs. $98 \pm 9 \mathrm{~mm}^{3}$ in vehicle vs. treatment group, respectively; $P<0.05, n=5$ per group), which demonstrates that infarct development was not merely delayed by the treatment.

Cyto D treatment confers greater protection in gelsolin-null mice. To evaluate the combined effects of cyto D administration and gelsolin gene deletion, we treated $\mathrm{gsn}^{-/-}$and $\mathrm{gsn}^{+/+}$ mice with cyto D $(1.0 \mu \mathrm{g}$ intracerebroventricularly $10 \mathrm{~min}$ utes before ischemia) or vehicle, respectively, and determined stroke outcome after two hours of MCA occlusion and 22 hours of reperfusion (Fig. 8). Compared with noninjected gsn ${ }^{-/-}$and gsn ${ }^{+/+}$mice (Fig. 3), vehicle-injected ani-

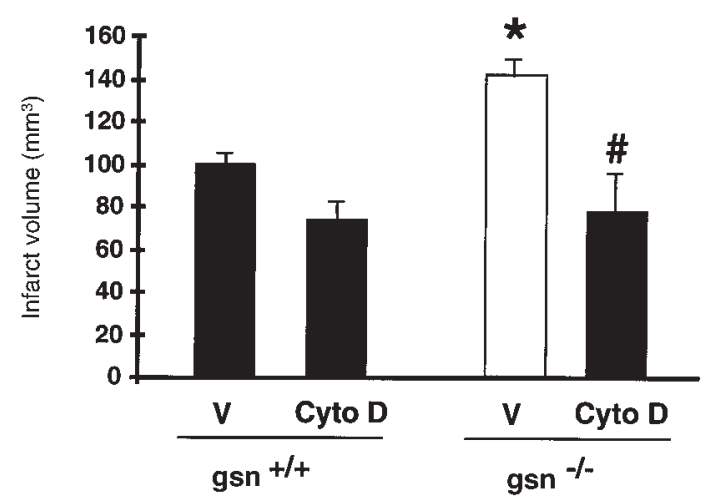

Figure 8

Combined effects of cyto $D$ treatment and gelsolin gene deletion on infarct size after MCA occlusion. Gsn ${ }^{+/+}$and $\mathrm{gsn}^{-/-}$mice were treated with cyto $D(1 \mu \mathrm{g}$ intracerebroventricularly $10 \mathrm{~min}$ before ischemia) or vehicle $(V)$, respectively, and then subjected to $2 \mathrm{~h}$ of left filamentous MCA occlusion and $22 \mathrm{~h}$ of reperfusion. Cerebral infarct volume was determined quantitatively as described $(22,24)$. Results were confirmed with the indirect method to determine infarct size as follows: $72.1 \pm 4.9 \mathrm{~mm}^{3}$ $\left(\mathrm{V} / \mathrm{gsn}^{+/+}\right)$vs. $44.7 \pm 8.2 \mathrm{~mm}^{3}$ (cyto $D / \mathrm{gsn}^{+/+}$) vs. $100.4 \pm 13.1 \mathrm{~mm}^{3}$ $\left(\mathrm{V} / \mathrm{gsn}^{-/-}\right)$vs. $45.4 \pm 11 \mathrm{~mm}^{3}$ (cyto $\left.\mathrm{D} / \mathrm{gsn}^{-/-}\right)$. Data are given as mean and $\mathrm{SE}\left(n=4-7\right.$ animals per group). ${ }^{*} P<0.01$ vs. vehicle-treated $\mathrm{gsn}^{+/+},{ }^{\#} P<$ $0.05 \mathrm{vs}$. vehicle-treated $\mathrm{gsn}^{-/-}$. ANOVA followed by Tukey's test. 
mals exhibited $\sim 10 \%-15 \%$ bigger direct infarcts, probably due to the intracerebroventricular injection. Remarkably, cyto $\mathrm{D}$ treatment led to a greater decrease in infarct size in the $\mathrm{gsn}^{-/}$mice compared with vehicle, such that infarcts in treated $\mathrm{gsn}^{-1-}$ mice did not differ significantly from treated $\mathrm{gsn}^{+/+}$mice. Hence, the cytoskeletal actions of gelsolin are likely to account for the differences seen in infarct size between $\mathrm{gsn}^{-/-}$and $\mathrm{gsn}^{+/+}$mice.

\section{Discussion}

Glutamate excitotoxicity and intracellular $\mathrm{Ca}^{2+}$ overload are thought to play a crucial role in neuronal death following cerebral ischemia (1-4). Here we demonstrated that $\mathrm{gsn}^{-/-}$mice are more susceptible to brain injury after ischemia/reperfusion than control mice, with significant differences in both infarction volume and brain swelling. This enhanced ischemic injury in the $\mathrm{gsn}^{-/}$mice appeared to be mediated by increased neuronal $\left[\mathrm{Ca}^{2+}\right]_{i}$, as shown by studies on cultured hippocampal $\mathrm{gsn}^{-/}$neurons. These cells exhibited increased cell death after glucose and oxygen deprivation, as well as a more rapid and sustained increase of $\left[\mathrm{Ca}^{2+}\right]_{\mathrm{i}}$ in comparison to wild-type neurons. In addition, depolarization-induced (and therefore VDCCmediated) increases in cytosolic $\mathrm{Ca}^{2+}$ levels in isolated cortical nerve terminals were also higher in the $\mathrm{gsn}^{-/-}$mice, and this difference was even more pronounced after ischemia/reperfusion. The observations extend our previous studies demonstrating higher NMDA- and VDCCmediated $\mathrm{Ca}^{2+}$ currents, as well as a lack of actin filament depolymerization in $\mathrm{gsn}^{-/-}$compared with wild-type neurons (15). Ischemia-induced cytoskeletal alterations known to be associated with increased $\mathrm{Ca}^{2+}$ influx, spectrin cleavage, and loss of MAP- 2 were exacerbated in the $\mathrm{gsn}^{-/-}$mice. Together, these data suggest that differences in ischemic susceptibility in the $\mathrm{gsn}^{-/}$mice probably relate to increased $\left[\mathrm{Ca}^{2+}\right]_{i}$ and $\mathrm{Ca}^{2+}$-mediated cellular damage, due to a lack of gelsolin-mediated actin filament depolymerization.

A second major finding was that the actin-depolymerizing compound cyto D protected 129/SV wild-type mice from brain ischemia and reduced infarct volume by $25 \%$ to $35 \%$. Moreover, when $\mathrm{gsn}^{-/}$mice were treated with cyto $\mathrm{D}$, infarct volume was reduced by nearly $50 \%$ and did not differ significantly from cyto D-treated $\mathrm{gsn}^{+/+}$mice. This observation confirms that it is the actin-depolymerizing activity of gelsolin that is critical in this process, accounting for the increased infarct volumes in $\mathrm{gsn}^{-/}$mice. In addition, we have also observed that gsn ${ }^{-/}$mice exhibit bigger lesions following striatal NMDA injections and that cyto D protects wild-type mice in this injury model (36) (Stagliano, N.E. et al., unpublished observations).

In view of these findings, we propose the following model (Fig. 9). Brain ischemia leads to brain hypoxia, acidosis, and glucose depletion, which promote neuronal depolarization, which, in turn, activates somadendritic as well as presynaptic voltage-dependent $\mathrm{Ca}^{2+}$ channels (VDCC) directly and NMDA receptors indirectly by glutamate release (1-4). This excitotoxic event leads to intracellular $\mathrm{Ca}^{2+}$ overload, a key trigger of cell injury and death (1-4). Gelsolin is activated by $\mathrm{Ca}^{2+}$ and acidosis $(\mathrm{pH}$ < 6.5) (37) to sever the neuronal actin filament network, leading to marked changes in the neuronal actin cytoskeleton and net actin depolymerization. These

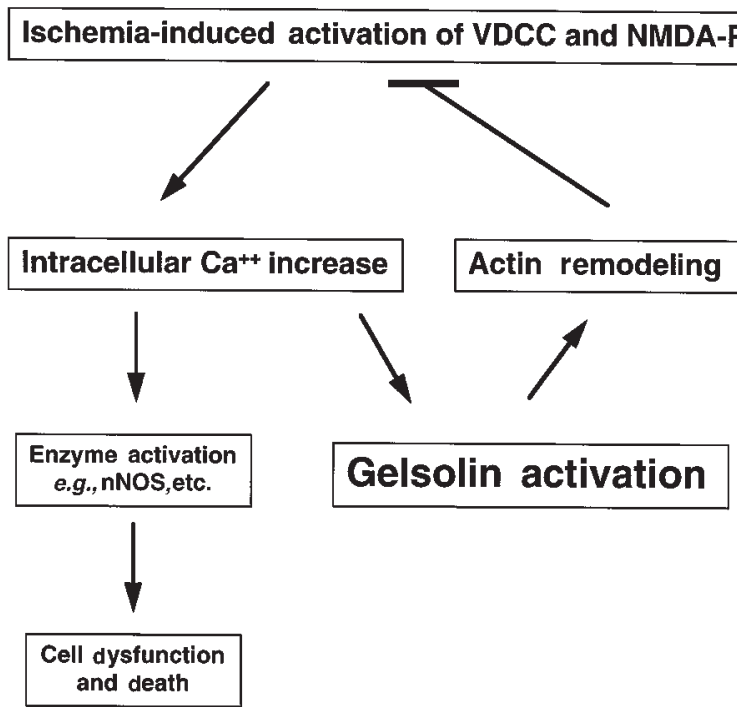

Figure 9

A model showing how gelsolin activation leading to dynamic changes in the actin cytoskeleton may modify tissue injury in cerebral ischemia. Brain ischemia promotes neuronal depolarization, which activates VDCC directly and NMDA channels by the release of glutamate. Activation of both channels mediates intracellular $\mathrm{Ca}^{2+}$ influx, which activates various cell death-promoting intracellular enzymes. $\mathrm{Ca}^{2+}$ also activates the actin-severing protein gelsolin, which in turn mediates dynamic changes (net depolymerization) in the actin filament network. This actin remodeling event leads to channel rundown, inactivation, and stabilization of $\left[\mathrm{Ca}^{2+}\right]$. Thus, gelsolin acts as an intracellular $\mathrm{Ca}^{2+}$ sensor, negatively regulating $\mathrm{Ca}^{2+}$ influx and thereby protecting against neuronal dysfunction and death. Cyto D, through similar effects on the actin cytoskeleton, also exhibits neuroprotective effects VDCC, voltage-dependent $\mathrm{Ca}^{2+}$ channels; NMDA, N-methyl-D-aspartate.

changes promote channel rundown by altering internal regulatory domains of VDCC and NMDA channels $(5,6)$, limiting further $\mathrm{Ca}^{2+}$-influx and stabilizing $\left[\mathrm{Ca}^{2+}\right]_{\mathrm{i}}(7,15)$. Thus, gelsolin activation and subsequent actin depolymerization are a response mechanism to brain ischemia that interrupts a progressive cycle of $\mathrm{Ca}^{2+}$-mediated cytotoxicity to protect against cell injury and death. The synergistic effects of acidosis and increased $\left[\mathrm{Ca}^{2+}\right]_{i}$ are particularly likely to activate gelsolin under these circumstances (37). This compensatory mechanism leads to both reduction in infarct volume and in surrounding edema, both of which are beneficial effects in stroke.

We recently demonstrated that gelsolin is a prominent substrate of activated caspase-3 (27), an apoptotic protease with a critical function in apoptosis in multiple cell types (38). Caspase-3 cleavage of gelsolin results in the generation of a constitutively active $\mathrm{NH}_{2}$-terminal fragment that severs actin filaments without $\mathrm{Ca}^{2+}$ regulation. Apoptosis develops during cerebral ischemia based on morphological, biochemical, pharmacological, and molecular criteria $(22,23,39,40)$, but its extent is highly dependent on the duration of the ischemic insult. Activation and cleavage of caspase- 3 was previously demonstrated in the mouse ischemia model used here (35). We demonstrated that gelsolin is cleaved during ischemia, and the appearance of gelsolin cleavage products followed a time course similar to that of caspase- 3 
activation (35), providing the first evidence that gelsolin is cleaved by capsase- 3 in vivo. However, the amount of cleavage was minimal in these whole brain extracts, consistent with limited apoptotic induction. Moreover, in contrast to our earlier study in which gelsolin cleavage accelerated apoptotic death in $\mathrm{gsn}^{+/+}$, compared with $\mathrm{gsn}^{-/}$, neutrophils (27), here we observed that $\mathrm{gsn}^{-/-}$mice exhibited enlarged infarcts. It is possible that during brain ischemia/reperfusion, gelsolin activation by caspase- 3 cleavage, as well as increased $\left[\mathrm{Ca}^{2+}\right]_{\mathrm{i}}$ and acidosis, facilitates a beneficial response to overactivation of NMDA and VDCC channels, explaining this organ/cell difference. Alternatively, we suspect that the gelsolin cleavage fragment had no significant effects in these cells under these conditions, given the limited extent of cleavage observed. Gelsolin is also reported to inhibit apoptosis when overexpressed in Jurkat cells, a human T-cell line (41), and it is possible that its neuronal expression also inhibits apoptosis. Analysis of the role of gelsolin in a recently developed model of mild ischemia, where apoptotic cell death is more pronounced than excitotoxic cell death (23), may provide further insight.

In conclusion, gelsolin expression at normal levels in the murine brain serves as protection from ischemic injury through its ability to drive dynamic changes in the neuronal actin cytoskeleton, to stabilize $\left[\mathrm{Ca}^{2+}\right]_{i}$, and to attenuate $\mathrm{Ca}^{2+}$-induced cytotoxicity. The observation that the partial gelsolin analogue, cytochalasin $\mathrm{D}$, reduced infarct volume by $25 \%$ in $\mathrm{gsn}^{+/+}$mice and by almost $50 \%$ in $\mathrm{gsn}^{-/}$mice, suggests that measures that increase or mimic gelsolin expression or activity in the brain may be beneficial during human brain ischemia.

\section{Acknowledgments}

The authors thank Ulrich Laufs for advice. Studies were supported by grants from the National Institutes of Health (NS10828 to M.A. Moskowitz; NS29001 and NS30583 to M.P. Mattson; and RO1 HL54188 and PO1 HL48743 to D.J. Kwiatkowski), and from the Deutsche Forschungsgemeinschaft (En343/1-1 to M. Endres).

1. Choi, D.W. 1995. Calcium: still center-stage in hypoxic-ischemic neuronal death. Trends Neurosci. 18:58-60.

2. Choi, D.W. 1988. Glutamate neurotoxicity and diseases of the nervous system. Neuron. 1:623-634.

3. MacDermott, A.B., Mayer, M.L., Westbrook, G.L., Smith, S.J., and Barker, J.L. 1986. NMDA-receptor activation increases cytoplasmic calcium concentration in cultured spinal cord neurons. Nature. 321:519-522.

4. Park, P.C., Nehls, D.G., Graham, D.I., Teasdale, G.M., and McCulloch, J. 1988. The glutamate antagonist MK-801 reduces focal ischemic brain damage in the rat. Ann. Neurol. 24:43-51.

5. Rosenmund, C., and Westbrook, G.L. 1993. Calcium-induced actin depolymerization reduces NMDA channel activity. Neuron. 10:805-814.

6. Johnson, B., and Byerly, L. 1993. A cytoskeletal mechanism for $\mathrm{Ca}^{2+}$ channel metabolic dependence and inactivation by intracellular $\mathrm{Ca}^{2+}$. Neuron . 10:797-804.

7. Furukawa, K., Smith-Swintosky, V.L., and Mattson, M.P. 1993. Evidence that actin depolymerization protects hippocampal neurons against excitotoxicity by stabilizing $\left[\mathrm{Ca}^{2+}\right]$ i. Exp. Neurol. 133:153-163.

8. Schafer, D.A., and Cooper, J.A. 1995. Control of actin assembly at filament ends. Ann. Rev. Cell Dev. Biol. 11:497-518.

9. Janmey, P.A., and Stossel, T.P. 1987. Modulation of gelsolin function by phosphatidylinositol 4,5-biphosphate. Nature. 325:362-364.

10. Kwiatkowski, D.J., Mehl, R., and Yin, H.L. 1988. Genomic organization and biosynthesis of secreted and cytoplasmic forms of gelsolin. J. Cell. Biol. 106:375-384.

11. Kwiatkowski, D.J., Janmey, P.A., and Yin, H.L. 1989. Identification of critical functional and regulatory domains in gelsolin. J. Cell. Biol. 108:1717-1726.
12. Azuma, T., Witke, W., Stossel, T.P., Hartwig, J.H., and Kwiatkowski, D.J. 1998. Gelsolin is a downstream effector of rac for fibroblast motility. EMBO J. 17:1362-1379.

13. Witke, W., et al. 1995. Hemostatic, inflammatory, and fibroblast responses are blunted in mice lacking gelsolin. Cell. 81:41-51.

14. Tanaka, J., Kira, M., and Subue, K. 1993. Gelsolin is localized in neuronal growth cones. Dev. Brain Res. 76:268-271.

15. Furukawa, K., et al. 1997. The actin-severing protein gelsolin modulates calcium channel and NMDA receptor activities and vulnerability to excitotoxicity in hippocampal neurons. J. Neurosci. 17:8178-8186.

16. Mattson, M.P., Dou, P., and Kater, S.B. 1988. Outgrowth-regulating actions of glutamate in isolated hippocampal pyramidal neurons. J. Neurosci. 8:2087-2100.

17. Mattson, M.P., Murrain, M., Guthrie, P.B., and Kater, S.B.1989. Fibroblast growth factor and glutamate: opposing actions in the generation and degeneration of hippocampal architecture. J. Neurosci. 9:3728-3740.

18. Mattson, M.P., Barger, S.W., Begley, J.G., and Mark, R.J. 1995. Calcium, free radicals, and excitotoxic neuronal death in primary cell culture. Methods Cell. Biol. 46:187-216.

19. Grynkiewicz, G., Poenie, M., and Tsien, R.Y. 1985. A new generation of $\mathrm{Ca}^{2+}$ indicators with greatly improved fluorescence properties. J. Biol. Chem. 260:3440-3450.

20. Gleitz, J., Beile, A., and Peters, T. 1996. ( \pm )-Kavain inhibits the veratridineand $\mathrm{KCl}$-induced increase in intracellular $\mathrm{Ca}^{2+}$ and glutamate-release of rat cerebrocortical synaptosomes. Neuropharmacology. 35:179-186.

21. Meder, W., Fink, K., and Göthert, M. 1997. Involvement of different calcium channels in $\mathrm{K}^{+}$- and veratridine-induced increases of cytosolic calcium concentration in rat cortical synaptosomes. Naunyn-Schmiedeberg's Arch. Pharmacol. 356:797-805.

22. Hara, H., et al. 1997. Inhibition of interleukin-1 $\beta$ converting enzyme family proteases reduces ischemic and excitotoxic damage. Proc. Natl. Acad. Sci. USA. 94:2007-2012.

23. Endres, M., et al. 1998. Attenuation of delayed neuronal death after mild focal ischemia in mice by inhibition of the caspase family. J. Cereb. Blood Flow Metab. 18:238-247.

24. Endres, M., Wang, Z.-Q., Namura, S., Waeber, C., and Moskowitz, M.A. 1997. Ischemic brain injury is mediated by the activation of poly(ADPribose)polymerase. J. Cereb. Blood Flow Metab. 17:1143-1151.

25. Huang, Z., et al. 1994. Effects of cerebral ischemia in mice deficient in neuronal nitric oxide synthase. Science. 265:1883-1885.

26. Swanson, R.A., et al. 1990. A semiautomated method for measuring brain infarct volume. J. Cereb. Blood Flow Metab. 10:290-293.

27. Kothakota, S., et al. 1997. Caspase-3-generated fragment of gelsolin: effector of morphological change in apoptosis. Science. 278:294-298.

28. Smith-Swintosky, V.L., et al. 1996. Metapyrone, an inhibitor of glucocorticoid production, reduces brain injury by focal and global ischemia and seizures. J. Cereb. Blood Flow Metab. 16:585-598.

29. Robert-Lewis, J.M., et al. 1994. Immunolocalization of calpain I-mediated spectrin degradation to vulnerable neurons in the ischemic gerbil brain. J. Neurosci. 14:3934-3944.

30. Pettigrew, L.C., et al. 1996. Microtubular proteolysis in focal cerebral ischemia. J. Cereb. Blood Flow Metab. 16:1189-1202.

31. Yao, H., et al. 1995. Local cerebral glucose utilization and cytoskeletal proteolysis as indices of evolving focal ischemic injury in core penumbra. J. Cereb. Blood Flow Metab. 15:398-408.

32. Belayev, L., Busto, R., Watson, B.D., and Ginsberg, D.M. 1995. Post-ischemic administration of HU-211, a novel non-competitive NMDA antagonist, protects against blood-brain barrier disruption in photochemical cortical infarction in rats: a quantitative study. Brain Res. 702:266-270.

33. Du, C., Hu, R., Hsu, C.Y., and Choi, W.D. 1996. Dextrorphan reduces infarct volume, vascular injury, and brain edema after ischemic brain injury. J. Neurotrauma. 13:215-222.

34. Baskaya, M.K., et al. 1997. Protective effects of ifenprodil on ischemic injury size, blood-brain barrier breakdown, and edema formation in focal cerebral ischemia. Neurosurgery. 40:364-370.

35. Namura, S., et al. 1998. Activation and cleavage of caspase-3 in experimental cerebral ischemia in mice. J. Neurosci. 18:3659-3668.

36. Ayata, C., et al. 1997. Reduced striatal NMDA excitotoxicity in type I nitric oxide synthase knockout mice. J. Neurosci. 17:6908-6917.

37. Lamb, J.A., Allen, P.G., Tuan, B.Y., and Janmey, P.A. 1993. Modulation of gelsolin function. Activation at low $\mathrm{pH}$ overrides $\mathrm{Ca}^{2+}$ requirement. $J$. Biol. Chem. 268:8999-9004.

38. Kuida, K., et al. 1996. Decreased apoptosis in the brain and premature lethality in CPP32-deficient mice. Nature. 384:368-372.

39. Li, Y., et al. 1995. Ultrastructural and light microscopic evidence of apoptosis after middle cerebral artery occlusion in the rat. Am. J. Pathol. 146:1045-1051.

40. Hill, I.E., MacManus, V., Rasquinha, I., and Tuor, U.I. 1995. DNA fragmentation indicative of apoptosis following unilateral cerebral hypoxia-ischemia in the neonatal rat. Brain Res. 676:398-403.

41. Ohtsu, M., et al. 1997. Inhibition of apoptosis by the actin-regulatory protein gelsolin. EMBOJ. 16:4650-4656. 